EDITORIAL

\title{
In This Issue: Access, Vulnerability, and Science
}

\author{
Jobn J. Frey III, MD, Associate Editor \\ Deborab J. Coben, PbD, Associate Editor \\ Ann Fam Med 2010;8:482-483. doi:10.1370/afm.1189.
}

VULN

\section{VERABILITY AND LEARNING}

ulnerability is an unavoidable human experience that can either sensitize us to experiences of patients and those we teach or wall us off from feelings and honest emotions. Three essays show sensitivity to vulnerability, and the lessons that emerge from the personal experiences of the authors can be influential. In the first essay, Bodenheimer reflects on his own physical and emotional experience managing chronic foot pain and how, as a seasoned chronic disease researcher, this experience opens new doors for him in understanding the emotional and psychological needs of the chronically ill. ${ }^{1}$ Similarly, in the second essay, Jones and Reis beautifully narrate how both teacher and student can grow and learn by revealing thoughts and emotions to each other during teaching interactions. ${ }^{2}$ In a third essay, McKersie shares his journal and reflections following Haitian relief work. ${ }^{3}$ His essay reminds us of the great capacity for resilience and courage that many people show in responding to profound pain and suffering. These 3 essays describe how learning emerges if one is open to the lessons that tender moments hold.

\section{GETTING TO THE DOCTOR-OR NOT}

Improved access is an expressed goal for practice redesign, but addressing access, it seems, may have unanticipated consequences. A major quality improvement

Conflicts of interest: none reported

\section{CORRESPONDING AUTHOR}

John J. Frey III, MD

Department of Family Medicine, Room 105

School of Medicine and Public Health

University of Wisconsin-Madison

800 University Bay Dr

Madison, WI 53705

john.frey@fammed.wisc.edu initiative in the Group Health Cooperative medical home project to improve access for chronic disease care by reducing clinician panel size required reassignment of some patients to new clinicians. Coleman et al found that reassigned patients were less likely to use primary care services and equally likely to use the emergency department. ${ }^{4}$ Although reassignment did not impair satisfaction, it did disrupt continuity for many and, as a result, did not foster the objectives of ensuring a medical home for these patients. Group Health is an integrated health system with a very stable population. One can imagine how their findings are amplified in the populations of patients that regularly switch providers as a result of insurance limitations. Such disruption is not only a phenomenon in the United States, however. Campbell et al describe the effects of policy and practice changes in the United Kingdom that were intended to improve patient access. The changes had some positive effects on access but negative effects on continuity ${ }^{5}$ - patients reported seeing their usual physician less often and gave lower ratings for care continuity and satisfaction.

In this issue, Nordin et al and Campos-Outcault et al, in 2 unique articles, examine access issues for adolescents and children. The study by Nordin et al reinforces the observation that access and care continuity can be illusive, particularly for certain types of patients. ${ }^{6}$ They use data from a large regional health system to describe the use of preventive services by adolescents and reinforce our perception that adolescents rarely use physician offices for preventive care during their teenage years. Our door may be open, but adolescents don't enter for a variety of reasons. ${ }^{7}$ A study by the American Academy of Family Physicians (AAFP) on access to childhood immunizations shows the wide variation by family physicians in use of immunizations in their practices. ${ }^{8}$ Cost, insurance, practice size, and access to public health all affect what parents might expect to be available for their children in a medical home. Not addressing these factors in a 
comprehensive fashion will increase the vulnerability of children in our country to suffer from inadequate preventive services.

\section{THE VALUE OF PRACTICE NETWORKS IN ASKING QUESTIONS}

We often see what might be adverse effects of common drugs not previously described, and because we are not clear how to pass this information to those who might need to know, a great deal of important data remain undocumented. Hickner et al used a national network of 24 practices to test a Web-based method of recording events relating to adverse drug effects or errors. ${ }^{9}$ The method appears to be effective in capturing data and not too disruptive to the flow of patient care.

The long held belief by physicians that drinking and sleep problems go together did not hold up in a study using the AAFP National Network. ${ }^{10}$ What did prove to be the case was that asking patients who said they drank to help sleep uncovered a population with a very high likelihood to be hazardous drinkers or people with alcohol problems. Asking about alcohol for sleep should be followed by asking in more detail about the role of alcohol in the patient's life.

\section{DESPERATELY SEEKING THE RIGHT CATEGORIZATION}

This issue of the Annals reports studies from groups of people defined by a category, such as by disease (a discussion of the perception of lung cancer patients about the roles of specialists and oncologists in care processes; a review of randomized controlled trials for a new supplemental drug that has not shown clinically significant improvement when compared with standards of care and may have more adverse outcomes of hypoglycemia in patients with type 1 and type 2 diabetes ), ${ }^{11,12}$ and sexual orientation (a review of care guidelines for gay, lesbian and bisexual patients). ${ }^{13}$ They all raise the central question of whether what these studies find applies to one's own practice. A clinician's goal is to provide care to each individual patient, and personal, patient-centered care requires the translation of the evidence from the studies of populations and subpopulations back to the patient facing the doctor at that moment. Deciding which patient categories or characteristics (race, ethnicity, sexual orientation, reaction to prescribed medications, behavioral groups) are the most relevant to an individual patient's health and well-being will always be the hard work of primary care. It will remain for clinicians to apply general findings to their specific populations. Evidence-based studies certainly help, but one of the real tasks of translational research is to build the science of mixedmethods, community-based research, where local knowledge and experience can inform research so that categories are more useful to the health of people in the specific practices and communities where we work.

\section{NEW EDITOR}

We are delighted to welcome James M. Gill, MD, $\mathrm{MPH}$, as a new associate editor. Jim is a family physician and co-owner of a small private practice in Wilmington, Delaware. He has a long history of conducting primary care health services research and is president of Delaware Valley Outcomes Research. His current focus is on issues related to the patient-centered medical home $(\mathrm{PCMH})$, and he is the co-chair of Delaware's statewide PCMH initiative. Dr. Gill is Associate Professor of Family Medicine at the Thomas Jefferson Medical College, Senior Scholar at the Thomas Jefferson School of Population Health, and Senior Policy Associate, University of Delaware College of Urban Affairs and Public Policy.

\section{References}

1. Bodenheimer T. Lessons from my left foot. Ann Fam Med. 2010; 8(6):550-551.

2. Jones K, Reis S. Learning through vulnerability: a mentor-mentee experience. Ann Fam Med. 2010;8(6):552-555.

3. McKersie RC. Snapshots of Haiti: a physician's relief work in a country in crisis. Ann Fam Med. 2010;8(6):556-558.

4. Coleman K, Reid RJ, Johnson E, et al. Implications of reassigning patients for the medical home: a case study. Ann Fam Med. 2010;8(6):493-498.

5. Campbell SM, Kontopantelis E, Reeves D, et al. Changes in patient experiences of primary care during health service reforms in England between 2003 and 2007. Ann Fam Med. 2010;8(6):499-506.

6. Nordin JD, Solberg LI, Parker ED. Adolescent primary care visit patterns. Ann Fam Med. 2010;8(6):511-516.

7. Campos-Outcalt D, Jeffcott-Pera M, Carter-Smith P, Schoof BK, Young HF. Vaccines provided by family physicians. Ann Fam Med. 2010;8(6):507-510.

8. Pridham KF, Hansen MF, Conrad HH. Anticipatory care as problem solving in family medicine and nursing. J Fam Pract. 1977;4(6): 1077-1081.

9. Hickner J, Zafar A, Kuo GM, et al. Field test results of a new ambulatory care medication error and adverse drug event reporting system-MEADERS. Ann Fam Med. 2010;8(6):517-525.

10. Vinson DC, Manning BK, Galliher JM, Dickinson LM, Pace WD, Turner BJ. Alcohol and sleep problems in primary care patients: a report from the AAFP National Research Network. Ann Fam Med. 2010;8(6):484-492.

11. Aubin $M$, Vezina $L$, Verreault $R$, et al. Family physician involvement in cancer care follow-up: the experience of a cohort of patients with lung cancer. Ann Fam Med. 2010;8(6):526-532.

12. Lee NJ, Norris SL, Thakurta S. Efficacy and harms of the hypoglycemic agent pramlintide in diabetes mellitus. Ann Fam Med. 2010; 8(6):542-549.

13. McNair RP, Hegarty K. Guidelines for the primary care of lesbian, gay, and bisexual people: a systematic review. Ann Fam Med. 2010; 8(6):533-541. 